\title{
Delineasi Patahan di Pulau Weh sebagai Perpanjangan The Great Sumatran Fault (GSF) Berdasarkan Data Metode Geomagnetik
}

\author{
Afrahun Naziah $^{(1, a)}$, Nazli Ismail ${ }^{(1, b)^{*}}$, Nasrullah Zaini ${ }^{(1, c)}$, dan Muhammad \\ $\mathrm{Nanda}^{(2, \mathrm{~d})}$ \\ (1)Physics Department, Faculty of Mathematics and Natural Science, Syiah Kuala University, Banda Aceh, \\ Indonesia, 23111 \\ ${ }^{(2)}$ Graduate School of Mathematics and Applied Sciences, Universitas Syiah Kuala, Indonesia, 23111 \\ Email : ${ }^{(a)}$ afrahul94@gmail.com, ${ }^{\left({ }^{*}\right)}$ nazli.ismail@unsyiah.ac.id, ${ }^{(c)}$ nasrullah.zaini@unsyiah.ac.id, \\ (d)m.nanda@mhs.unsyiah.ac.id
}

Diterima (05 Juli 2021), Direvisi (26 Juli 2021)

\begin{abstract}
This research has mapped the active fault of the Seulimeum segment part of the extension of The Great Sumatran Fault (GSF) in the northern as preparation for disaster mitigation. Nevertheless, seismic activity significantly on the Seulimeum segment still has not happened yet. This situation has the potential for a hugely destructive earthquake with a magnitude reaching 7.4 and also will threaten the Weh island at the northernmost end of the Seulimeum segment even though the Weh island is a settlement, integrated economy area, tourism, trade area, and freeport zone. This study used geophysical methods, i.e., geomagnetic methods, for subsurface investigation. Each distance of 500m data was measured throughout the island using the Proton Precession Magnetometer (PPM) GEM 19 to get 204 total magnetic field data. The correction process (e.g., diurnal and IGRF) is done to get the total intensity of magnetic anomalies. Based on the calculation of residual data and analytical signals from the intensity of total magnetic anomalies, Interpretation found 13 fault distributions around the island with orientation in the northwest-southeast. This result has in agreement with the previous studies. However, this research has did not yet got information about geometry and fault depth. Comprehensive research is needed to complete it.
\end{abstract}

Keywords: The Great Sumatran fault, Seulimuem segment, geomacnetic, Weh island.

Abstrak. Salah satu upaya dalam persiapan mitigasi bencana adalah pemetaan patahan yang diduga aktif. Penelitian ini telah memetakan perpanjangan patahan aktif The Great Sumatran Fault (GSF) dari Segmen Seulimeum. Meskipun Segmen Seuliemuem merupakan bagian dari GSF yang sangat aktif dibagian selatan Sumatera, namun aktivitas seismik secara signifikan dibagian segmen seulimeum masih belum terjadi. Hal ini diperkirakan berpotensi menghasilkan gempa besar dengan magnitudo mencapai 7.4. Keadaan ini juga mengancam Pulau Weh yang berada di ujung bagian utara dari Segmen Seulimeum. Padahal Pulau Weh merupakan kawasan pemukiman, ekonomi terpadu, pariwisata dan pelabuhan bebas. Penelitian ini menggunakan metode geofisika yaitu metode geomagnetic untuk investigasi bawah permukaan. Pendekatan metode geofisika dari metode magnetik dilakukan untuk melengkapi dan memperbaharui temuan pada penelitian-penelitian sebelumnya terkait distribusi patahan dan perpanjangan Segmen Seulimeum dari GSF. Pengambilan data dilakukan sebanyak 204 titik dengan jarak antar titik \pm 500 meter di seluruh Pulau Weh menggunakan Proton Precession Magnetometer (PPM) GEM 19. Data hasil pengukuran kemudian dilakukan koreksi International Geomagnetic Reference Field (IGRF) dan diurnal untuk mendapatkan nilai anomali intensitas magnetik total di Pulau Weh. Hasil interpretasi berdasarkan pengukuran efek regional dan perhitungan signal analytik didapatkan sebaran patahan sebanyak 13 patahan dengan orientasi timur laut-tenggara Pulau Weh. Temuan distribusi patahan ini mengikuti pola kesesuaian dengan kajian sebelumnya yang hanya memanfaatkan data permukaan saja. Meskipun demikian, penelitian ini belum mendapatkan informasi terkait geometri dan kedalaman patahan. Kajian lanjutan diperlukan untuk melengkapi informasi tersebut.

Kata kunci: Patahan Sumatera, Segmen Seulimuem, geomagnetik, Pulau Weh. 


\section{PENDAHULUAN}

Perpanjangan patahan aktif The Great Sumatran Fault (GSF) yang berada di bagian utara Aceh terbagi menjadi dua cabang, yaitu segmen Aceh dan segmen seulimeum [1]. Segmen Aceh mengarah ke Pulo Aceh disisi kiri dan disisi kanan yaitu segmen Seulimeum yang melintasi Pulau Weh di lepas pantai utara Aceh hingga menuju ke Laut Andaman [2] (Gambar. 1a). Keberadaan Pulau Weh terletak di dalam inner volcanic arc dari Pulau Sumatra [4], [5], bahkan sebelum Pleistosen, Pulau Weh adalah gunung berapi yang menjadi bagian dari Pulau Sumatra, letusan besar akhirnya memisahkan Pulau Weh dari Pulau Sumatra [6].

Tatanan geologi di Pulau Weh sangat dipengaruhi oleh oleh GSF [6], [7]. Secara geologis, pulau ini dibentuk oleh batuan andesit dan basaltik (58\%), batuan vulkanoklastik (30\%), serta terumbu karang dan aluvium (12\%) [8]. Secara detail ditampilkan pada Gambar 1b. Meskipun Pulau Weh merupakan bagian dari patahan aktif dari Segmen Seulimeuem di bagian utara GSF, namun rekaman gempa bumi besar yang signifikan $(\mathrm{M} \geq 7.0)$ [9] belum terjadi dalam kurun waktu 185 tahun [10]. Hal ini mengidentifikasi seismic gap di Segmen Seulimeum tersebut [11], [12], Sehingga berpotensi gempa bumi dengan magnitudo sekitar $~ 7.4$ [12]. Keadaan ini akan mengancam Pulau Weh yang berada di bagian utara dari Segmen Seulimeum.
Padahal, Pulau Weh merupakan area penting pada wilayah Aceh. Pulau Weh merupakan kawasan pemukiman [13], kawasan pariwisata [14], kawasan ekonomi terpadu [15] dan Pelabuhan bebas [16]. Oleh karena itu pemetaan distribusi patahan di Pulau Weh sangat mendesak untuk dilakukan. Sejauh ini penelitian di lepas pantai utara Aceh dan Pulau Weh masih minim dan parsial, seperti tektonik landform dan aktivitas paleo-seismik [17], pemetaan patahan berdasarkan unit geologi [6], kajian geometri dan kinematika patahan [5], Aceh [4] dan distribusi patahan berdasarkan kajian geomorfologi [18]. Bagaimanapun, kajian seperti pemetaan patahan berdasarkan kajian geomorfologi hanya berdasarkan kondisi atas permukaan saja, kajian - kajian geofisika yang mengidentifikasi berdasarkan struktur bawah permukaan perlu dilakukan untuk membandingkan hasil temuan. Penelitian ini telah melakukan pemetaan distribusi patahan berdasarkan data geofisika yaitu metode geomagnetik.

Penggunaan metode magnetik juga sangat cocok pada area yang luas, nondestructive, proses akuisisinya mudah, cepat dan ekonomis serta memiliki mobilitas yang tinggi [19]. Metode geofisika seperti metode magnetik ini merupakan salah satu metode yang paling efektif untuk delineasi patahan [20]. Selain itu penggunaan metode ini juga telah banyak diterapkan pada bidang kajian lain seperti: geothermal [21], ekplorasi [22], hingga bidang arkelogi [23]. 


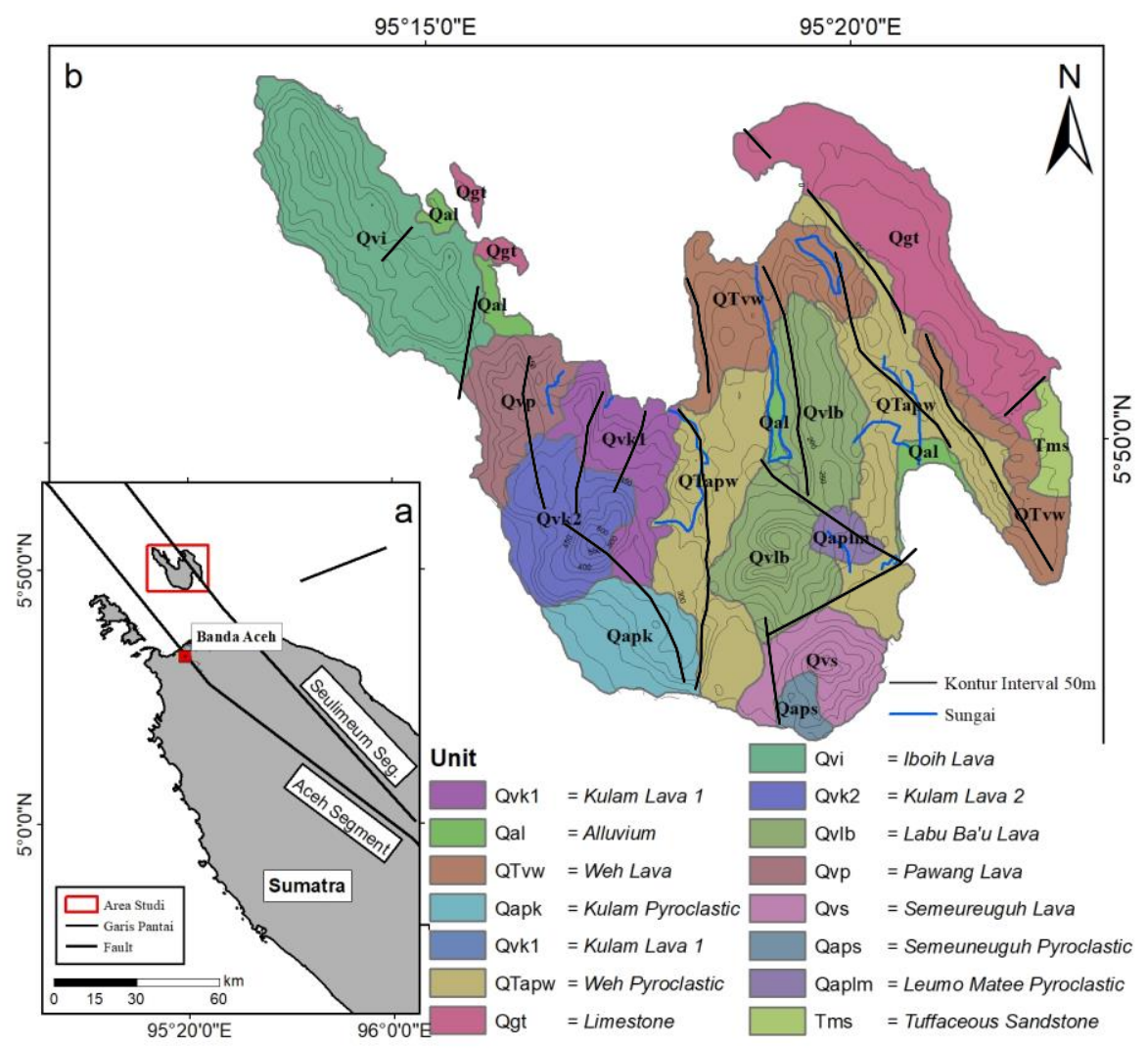

Gambar 1. Lokasi penelitian (a) area bagian utara Pulau Sumatra (b) tatanan geologi pada area penelitian (modifikasi berdasarkan [6]).

\section{METODE PENELITIAN}

Proses pengukuran data intensitas medan magnetik total dilakukan di seluruh Pulau Weh. Titik akuisisi data diterapkan secara grid acak dengan spasi $\pm 500 \mathrm{~m}$ sepanjang jalan yang dapat dilalui di seluruh Pulau Weh. Terdapat 204 titik akuisisi data di seluruh Pulau Weh. Beberapa area tidak dapat diakses saat proses akuisisi data dilakukan. Hal ini dikarenakan jalur akses yang terbatas, kawasan hutan dan pegunungan yang terjal serta kawasan militer yang tidak dapat dimasuki. Faktor ini menyebabkan beberapa area mengalami kekosongan data. Interpolasi data secara krigging [24], [25] dilakukan untuk melengkapi informasi.

Akuisisi data intensitas medan magnetik total menggunakan dua buah Proton Precession Magnetometer (PPM)
GEM 19 dengan sensitivitas mencapai 0.1 nT [26]. Satu unit instrumen PPM GEM 19 diletakkan di base dan satu unit lagi sebagai instrumen mobile. Data yang diperoleh dari hasil akuisi lapangan kemudian dilakukan koreksi medan magnet utama bumi (IGRF) berdasarkan Persamaan $\mathbf{1}$ dan koreksi harian (diurnal) berdasarkan Persamaan 2.

$$
\begin{aligned}
& H_{\text {corr }}=H_{\text {rover }}-\Delta H_{\text {diurnal }} \\
& \Delta T=H_{\text {rover }} \pm \Delta H_{\text {diurnal }}-H_{I G R F}
\end{aligned}
$$

dengan, $H_{\text {corr }}$ merupakan medan magnet terkoreksi, $\mathrm{H}_{\text {rover }}$ adalah bacaan medan magnet yang terukur di lapangan, $\Delta \mathrm{H}_{\text {diurnal }}$ adalah nilai koreksi diurnal. $\Delta T$ merupakan anomali medan magnet total, $H_{\text {rover }}$ yaitu medan magnet terukur di lapangan, $\Delta H_{\text {diurnal }}$ yaitu nilai koreksi diurnal. 

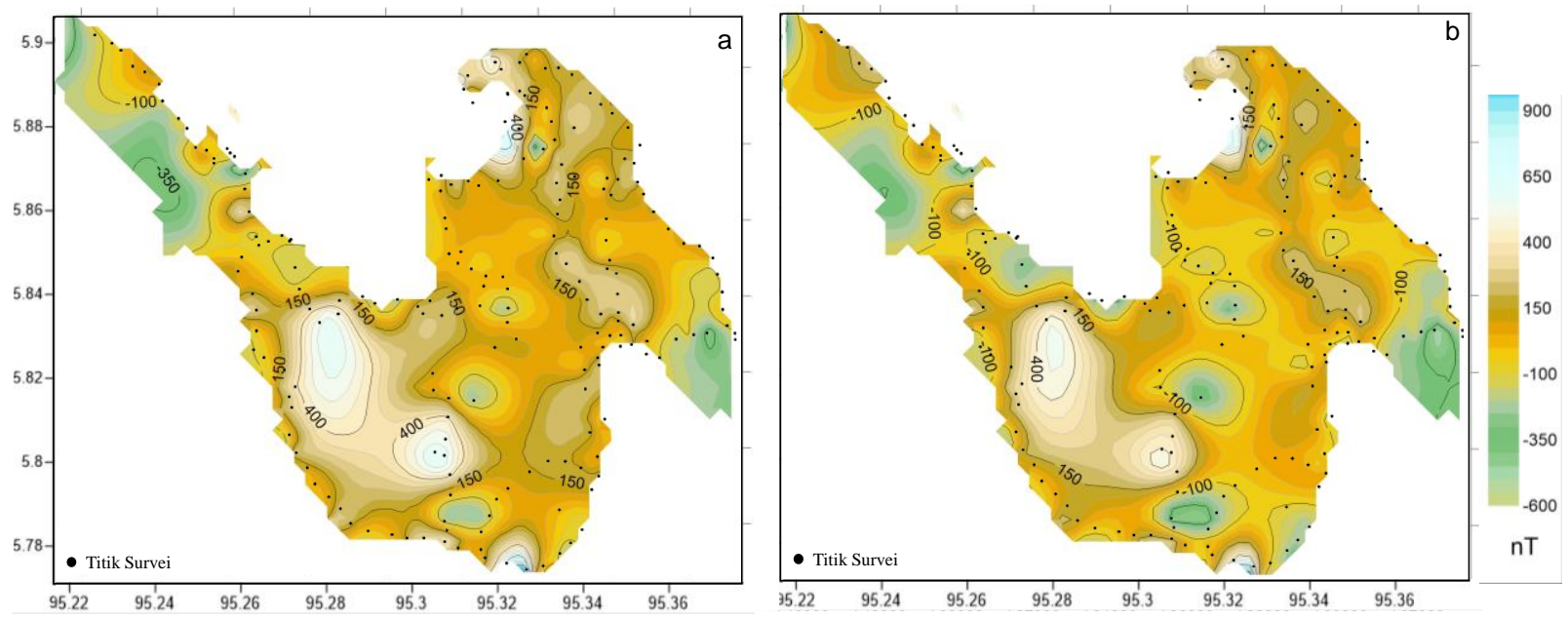

Gambar 2. (a) anomaly medan magnetic total (b) Residul medan magnetic

\section{HASIL DAN PEMBAHASAN}

Data intensitas medan magnetik dari pengukuran di Pulau Weh ditampilkan pada Gambar 2a. Melalui proses koreksi data, hasil yang ditampilkan tidak lagi dipengaruhi oleh sumber medan magnetik luar. Berdasarkan pengamatan, mayoritas sebaran nilai di seluruh pulau berada pada interval -100 s/d $450 \mathrm{nT}$ (indikator jinggakekuningan). Sebaran nilai terendah ditemukan disisi timur pada ujung arah tenggara (-600 s/d -200 nT, indikator warna kehijauan). Sedangkan nilai terendah disisi barat pulau juga terletak di ujung barat laut. Sebaran nilai anomali tinggi ditemukan di sisi timur pulau pada arah ujung barat laut hampir menuju ke tenggara pulau di sisi timur (600 s/d 900 nT, indikator kebiruan). Pada sisi barat nilai tertinggi ditemukan bagian tengah pada arah menuju ke selatantenggara.

Intensitas anomali medan magnetik mencirikan sifat kemagnetan dari target yang dicari. Namun, intensitas anomali medan magnetik tersebut masih dipengaruhi oleh faktor lingkungan sekitar, proses pemisahan anomali sekitar harus dilakukan untuk mendapat anomali residual. Intensitas anomali residual dipengaruhi oleh struktur dangkal sedangkan intensitas anomali residual dipengaruhi oleh struktur yang dangkal [27]. Terdapat banyak pendekatan untuk menyelesaikan hal ini, salah satunya menggunakan pemisahan berdasarkan kuadrat terkecil yang sesuai dengan polynomial orde rendah ke bidang yang diamati [28], [29]. Perhitungan polynomial paling efektif dilakukan dibandingkan beberapa perhitungan lainnya [30]. Hasil perhitungan dari anomali residual dari intensitas magnetik total ditampilkan pada Gambar 2b. Berdasarkan pola sebaran, distribusi peta anomali residual memiliki pola kemiripan dengan peta sebaran intensitas anomali magnetik total.

Meskipun demikian, proses interpretasi data tidak langsung dapat dilakukan. Pada tahapan pengolahan data ini, pola kontur yang dihasilkan belum mencirikan keberadaan benda anomali di daerah penelitian. Peta intensitas anomali total masih bersifat dipole. Keadaan dipole ini menyebabkan sebaran nilai anomali selalu berpasangan, karena kedua kutub berdekatan. Untuk menyelesaikan masalah tersebut, pengolahan data lanjutan harus dilakukan untuk mengubah anomali dipole menjadi monopole, seperti perhitungan transformasi signal analytic salah satunya. 


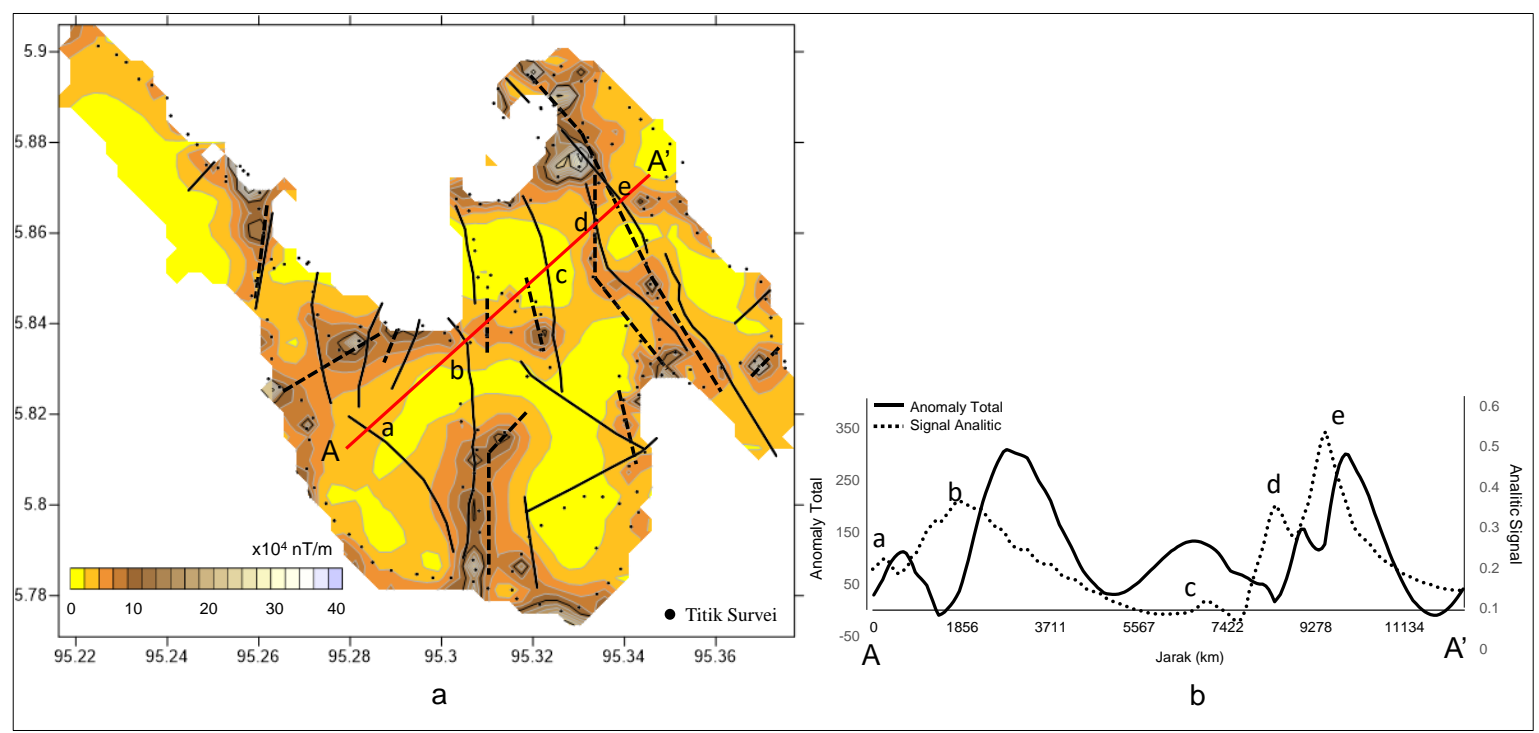

Gambar 3. (a) Distribusi intepretasi medan magnetic total berdasarkan tranformasi analytic signal. Garis hitam solid adalah interpretasi patahan berdasarkan kajian geomorfologi [18]. Garis hitam putus putus adalah interpretasi patahan berdasarkan signal analytic (b) profil penampang A-A'.

Transformasi signal analytic (As) dilakukan berdasarkan akar kuadrat dari jumlah turunan vertikal - horizontal dan dua ortogonal medan magnet [31]. Transformasi ini menyederhanakan data anomali medan magnetik $(T)$ yang sedikit terpengaruhi keberadaannya pada pengukuran daerah lintang rendah. Perhitungan dari transformasi signal analytic didasarkan pada Persamaan 3.

$$
A s(x, y)=\sqrt{\left(\frac{\partial T}{\partial x}\right)^{2}+\left(\frac{\partial T}{\partial z}\right)^{2}}
$$

Hasil transformasi pada kajian ini ditampilkan pada Gambar 3a dengan kisaran nilai dari signal analytic berada pada 0 s/d $360000 \mathrm{nT} / \mathrm{m}$. Pada tahap ini beberapa bagian telah terlihat kontras nilai magnetik dari hasil transformasi, seperti di ujung arah timur laut dan ujung tenggara pada sisi timur Pulau Weh. Kemudian di bagian selatan pada bagian tengah Pulau Weh, serta di tengah dan ke arah barat laut pada sisi barat Pulau Weh. Nilai kontras tersebut diperkirakan menunjukkan target yang dicari. Pada Gambar 3a. kontras anomali pada perhitungan signal analytic ditandai sebagai garis hitam putus - putus. Proses pembandingan dengan pemetaan dari kajian sebelumnya juga dilakukan yang ditampilkan pada garis hitam solid. Berdasarkan hasil temuan, terdapat 13 patahan diseluruh pulau. Hasil analisis menunjukkan bahwa distribusi patahan pada penelitian terdahulu berdasarkan geomorfologi menunjukkan korelasi yang bersesuaiakan dengan penelitian geomagnetik. Meskipun demikian, beberapa tempat juga mengalami kesenjangan informasi dari kedua hasil interpretasi.

Pada salah satu sisi Pulau Weh, diterapakan sayatan yang memotong patahan sehingga menghasilkan profil penampang A-A' sepanjang $12.300 \mathrm{~m}$ (Gambar 3b). Pada profil yang ditampilkan pada Gambar 3b menunjukkan hasil anomali medan magnetik dan perhitungan signal analytic. Keberadaan patahan dari hasil perhitungan signal analytic ditandai pada setiap puncak grafik. Hal ini ditandai sebagai a, b, c, d dan e sepanjang profil. Keberadaan patahan pada profil A-A' menunjukkan kesesuaian pada diskontinuitas hasil pada Gambar $3 \mathbf{b}$. 


\section{KESIMPULAN}

Hasil interpretasi didapatkan sebaran patahan di Pulau Weh sekitar 13 patahan. Secara umum, hasil temuan distribusi patahan pada penelitian ini mengikuti pola sebaran patahan pada kajian terdahulu berdasarkan geomorfologi [18]. Namun, beberapa patahan yang ditampilkan pada kajian geomorfologi tersebut tidak ditemukan pada interpretasi hasil pada penelitian ini. Pada dasarnya penelitian geomorfologi hanya mengkaji keadaan atas permukaan saja, sedangkan kajian geofisika seperti metode magnetik pada kajian ini dapat menganalisis keadaan bawah permukaan.

Orientasi patahan yang didapatkan pada penelitian ini dominan pada arah timur laut - tenggara. Hal ini menunjukkan kesesuaian dengan arah patahan GSF di Pulau Sumatra [1]. Beberapa juga mengemukakan bahwa Pulau Weh merupakan area perpanjangan dari GSF di lepas pantai utara Aceh (misalnya: [17], [18], [32], [33]).

\section{UCAPAN TERIMAKASIH}

Para penulis ingin mengucapkan terima kasih kepada tim penelitian dan kepada Direktorat Jenderal Pendidikan Tinggi Kementerian Pendidikan dan Kebudayaan Republik Indonesia untuk mendanai penelitian ini melalui hibah penelitian PMDSU

\section{DAFTAR PUSTAKA}

[1] K. Sieh and D. Natawidjaja, "Neotectonics of the Sumatran fault, Indonesia," Journal of Geophysical Research, vol. 105, no. B12. p. 28295, 2000, doi: 10.1029/2000JB900120.

[2] J. R. Curray, "Tectonics and history of the Andaman Sea region," $J$. Asian Earth Sci., vol. 25, pp. 187232, 2005, doi: 10.1016/j.jseaes.2004.09.001.

[3] J. R. Curray, "Tectonics and history of the Andaman Sea region," $J$. Asian Earth Sci., vol. 25, no. 1, pp. 187-232, 2005, doi: 10.1016/j.jseaes.2004.09.001.

[4] D. Ghosal, S. C. Singh, A. P. S. Chauhan, and N. D. Hananto, "New insights on the offshore extension of the Great Sumatran fault, NW Sumatra, from marine geophysical studies," Geochemistry, Geophys. Geosystems, vol. 13, no. 1, pp. 1-18, 2012, doi: 10.1029/2012GC004122.

[5] D. Fernández-Blanco, M. Philippon, and C. von Hagke, "Structure and kinematics of the Sumatran Fault System in North Sumatra (Indonesia)," Tectonophysics, vol. 693, no. 2015, pp. 453-464, 2016, doi: 10.1016/j.tecto.2016.04.050.

[6] S. Dirasutisna and R. Hasan, "Geologi Panas Bumi Sabang, Kota Sabang., Provinsi Aceh, Nanggroe Darussalam," Pemaparan Has. Kegiat. Survei Panas Bumi, pp. 1-6, 2005.

[7] Barber and Crow, "Sumatra: geology, resources and tectonic evolution (references)," Tectonics, vol. 21, no. 5, p. 1040, 2005.

[8] H. Kurnio, I. Syafri, A. Sudradjat, M. F. Rosana, and M. Resources, "Indonesian journal on geoscience," Indones. J. Geosci., vol. 3, no. 3, pp. 173-182, 2016, doi: 10.17014/ijog.3.3.173-183.

[9] N. Hurukawa, B. R. Wulandari, and M. Kasahara, "Earthquake history of 
the Sumatran fault, Indonesia, since 1892, derived from relocation of large earthquakes," Bull. Seismol. Soc. Am., vol. 104, no. 4, pp. 1750 1762, 2014, doi: $10.1785 / 0120130201$.

[10] O. Bellier et al., "Paleoseismicity and seismic hazard along the Great Sumatran fault (Indonesia), ' $J$. Geodyn., vol. 24, no. 1-4, pp. 169183, 1997, doi: 10.1016/s02643707(96)00051-8.

[11] D. H. Natawidjaja and W. Triyoso, "The Sumatran Fault Zone - From Source To Hazard," J. Earthq. Tsunami, vol. 01, no. 01, pp. 21-47, 2007 , doi: 10.1142/s1793431107000031.

[12] T. Ito et al., "Isolating along-strike variations in the depth extent of shallow creep and fault locking on the northern Great Sumatran Fault," J. Geophys. Res. Solid Earth, vol. 117, no. 6, pp. 1-16, 2012, doi: 10.1029/2011JB008940.

[13] Badan Pusat Statistik, Statistik Indonesia 2018. Badan Pusat Statistik, 2018.

[14] DISBUDPAR, "Aceh Mulai Dilirik Wisatawan Mancanegara," Culture and Tourism Office, Aceh Government, 2018. disbudpar.acehprov.go.id (accessed Mar. 01, 2019).

[15] Peraturan Presiden RI, Integrasi ekonomi terpadu. Indonesia: Republic of Indonesia, 1998.

[16] Undang - Undang RI, Perdangan dan pelabuhan Sabang. Indonesia, 2000.

[17] H. Tsutsumi, Y. Soeda, N. Ismail, B.
Ali, and T. Tabei, "Tectonic Landform and Paleoseismic Activity of the Northernmost Sumatran Fault, Aceh Province , Indonesia," $J$. Geophys. Res. Earth, 2020, doi: https://doi.org/10.1002/essoar.10504 162.2.

[18] M. Nanda, S. Rizal, F. Abdullah, R. Idroes, and N. Ismail, "Mapping Faults Distribution Based on Dem Data for Regional Spatial Plan Assessment of Sabang Municipality, Indonesia," Int. J. GEOMATE, vol. 19, no. 76, pp. 197-204, 2020.

[19] J. . Reynolds, An Introduction to Applied and Environmental Geophysics, 2nd ed. UK: Chichester: John Wiley and Sons Ltd, 2011.

[20] S. E. Scheiber-enslin, "Stephanie E. Scheiber-Enslin Integrated Geophysical Investigation of the Karoo Basin, South Africa," no. August, 2015.

[21] J. Drolet, B. Giroux, and C. Bouligand, "Estimating the Curie point depth using aeromagnetic data with a fractal model in the Province of Québec , Eastern Canada b," EGU Gen. Assem., no. November, pp. 6970, 2017.

[22] O. Menshov, R. Kuderavets, and I. Chobotok, "Magnetic and mineralogy analysis of soils of hydrocarbon prospective areas in Ukraine," 24th Eur. Meet. Environ. Eng. Geophys., no. September, 2018, doi: 10.3997/2214-4609.201802652.

[23] A. Asyqari, D. Sugiyanto, M. Yanis, F. Abdullah, and N. Ismail, "Mapping of archaeological structure along east-coast of Aceh Besar District, Indonesia based on total magnetic field anomalies," IOP 
Conf. Ser. Earth Environ. Sci., vol. 348, no. 1, 2019, doi: 10.1088/17551315/348/1/012041.

[24] R. Webster and M. A. Oliver, Statistical Methods in Soil And Land Resource Survey, no. 1. 1990.

[25] M. L. Stein, Interpolation of Spatial Data: Some Theory for Kriging. Chicago, IL 60637: Springer, 2012.

[26] GEM System, "Instruction Manual GSM 19 v.7.0,” Advanced Magnetometers, Canada, 2008.

[27] Telford, Applied Geophysics. Cambridge: Cambridge University Press, 1990.

[28] Y. Li and D. W. Oldenburg, "3-D inversion of magnetic data," 1993 SEG Anпu. Meet., vol. 61, no. 2, pp. 400-402, 1993, doi: $10.1190 / 1.1822498$.

[29] H. Gabtni and C. Jallouli, "Regionalresidual separation of potential field: An example from Tunisia," J. Appl. Geophys., vol. 137, pp. 8-24, 2017, doi: 10.1016/j.jappgeo.2016.12.011.

[30] A. I. Obasi, A. O. I. Selemo, and J.
S. Nomeh, "Gravity models as tool for basin boundary demarcation: A case study of Anambra Basin, Southeastern Nigeria," J. Appl. Geophys., vol. 156, pp. 31-43, 2018, doi: 10.1016/j.jappgeo.2017.11.002.

[31] N. Debeglia and J. Corpel, "Automatic 3-D interpretation of potential field data using analytic signal derivatives," Geophysics, vol. 62, no. 1, pp. 87-96, 1997, doi: $10.1190 / 1.1444149$.

[32] D. Ghosal, S. C. Singh, A. P. S. Chauhan, and N. D. Hananto, "New insights on the offshore extension of the Great Sumatran fault, NW Sumatra, from marine geophysical studies," Geochemistry, Geophys. Geosystems, vol. 13, no. 1, pp. 1-18, 2012, doi: 10.1029/2012GC004122.

[33] S. Awad, S. Araffa, and F. A. Monteiro, "Delineating active faults by using integrated geophysical data at northeastern part of Cairo , Egypt," no. 2012, pp. 33-44, 2013. 